\title{
Determination of quality parameters in apple 'Smoothee Golden Delicious' using backscattering laser imaging
}

\author{
Victoria Lafuente ${ }^{1,2}$, Jesús Val $^{1}$, Concha Urzola ${ }^{2}$, Ignacio Negueruela ${ }^{2}$ \\ ${ }^{1}$ Estación Experimental de Aula Dei (CSIC). Departamento de Nutrición Vegetal. Avda. Montañana, 1005 C.P. 50059, \\ Zaragoza \\ ${ }^{2}$ Departamento de Física Aplicada. Facultad de Veterinaria. Universidad de Zaragoza. Calle Miguel Servet 177, C.P \\ 50013, Zaragoza \\ mvlafuente@ipe.csic.es
}

\begin{abstract}
The objective of this study was to evaluate 'Smoothee Golden Delicious' apples, using backscattering images as a nondestructive method to estimate some quality parameters during the ripening process of fruit.

In this experiment, 208 apples were collected from Aula Dei Experimental Station (CSIC) in Zaragoza (Northeastern, Spain). Backscattering images were taken from samples collected every 15 days for 7 months until harvest. Fruits soluble solids contents (SSC) and firmness were measured by traditional destructive methods. The light source was a solid state laser diode module emitting at three different spectral bands $(670,785$ and $980 \mathrm{~nm})$

PLS calibration methods were used to create the statistical model to predict SSC and firmness. Good results were obtained when PLS calibration was applied to Feret diameter corresponding at different levels of gray. The $\mathrm{R}_{\mathrm{cv}}{ }^{2}$ values were 0.87 for firmness and 0.93 for $\mathrm{SSC}$, which are higher than other values previously reported in the literature for the same crop.
\end{abstract}

Keywords: Multispectral imaging, Backscattering, fruit

\section{INTRODUCTION}

Fruit quality has been evolving throughout time. At present, fruit production and commercialization extend to deliver criteria to which the consumer imposes (Vallejo, 1990). Setting the proper harvest date is not only useful in obtaining a better product, but also increases production. The main changes during ripening are color, flavour and texture. The quality indices most often used to determinate fruit quality are color, firmness and soluble solids content (SSC). Traditionally, firmness was determinated by the destructive method Magness-Taylor and refractometry respectively. The main advantages of these techniques are that they present a good correlation with the organoleptic characteristics of the fruit (López et al, 2000), and their problem is they are destructive.

In recent years, non-destructive methods have been developed for estimating fruit parameters with the aim of replacing the destructive ones. The most practical and satisfactory techniques for the non destructive quality evaluation of agricultural products are the techniques obtained from optical spectrometry (Chen, 1996) such us Near Infrared Spectroscopy (NIR), Fast Fourier Transform NIR (FTNIR) and laser light backscattering image analysis. A lot of researchers have studied laser light backscattering which are obtained by a laser to predict quality indexes in fruit (Qing et al, 2007; Peng et al, 2006; Tu et al, 1995; McGlone et al 1997).

Scattering is a physical phenomenon that is more closely associated with the structure of fruit tissue (Lu, 2004). Light scattering is dependent on the density, cell structures and intra-cellular matrices of fruit, captured onto an image.

8th Iberoamerican Optics Meeting and 11th Latin American Meeting on Optics, Lasers, and Applications,

edited by Manuel Filipe P. C. Martins Costa, Proc. of SPIE Vol. 8785, 8785DO

(C) 2013 SPIE · CCC code: $0277-786 X / 13 / \$ 18 \cdot$ doi: $10.1117 / 12.2026376$ 
Therefore, light scattering is expected to be useful in quantifying certain mechanical and textural properties of fruit, such us firmness (Lu and Peng, 2006).

Multivariable regression methods ('Multiple Linear Regression' (MLR), 'Principal Components Regression' (PCR) y Partial Least Squares (PLS)) are used to correlate backscattering laser images to the physical and chemical properties of fruit.

The objective of this work was to get the soluble solid content and firmness prediction for 'Smoothee Golden Delicious' apple, using monochromatic backscattering imaging. For this purpose, a laser light source providing three wavelenghts. Partial Least Square (PLS) regression was carried out and applied on a test-set to evaluate the performance of calibration models using average diameter of Feret corresponding at different levels of gray.

\section{MATERIALS AND METHODS}

\section{Samples}

The experiment was performed on the Apple cultivar 'Smoothee Golden Delicious', in an experimental orchard, in Zaragoza, Spain. Trees were planted in a $5 \times 3$ frame. Fertigation was performed by local drip. Samples were harvested every 15 days between May and October 2012. Backscattering images were taken and destructive methods were performed to determinate SSC and firmness.

\section{Multispectral images}

Multispectral images were obtained by a monochromatic camera CCD, (BASLER A310f (Germany) sensitive Vis-NIR (360-1000 nm)). The samples get ready in a device that allowed obtaining a backscattering area of $25 \mathrm{~mm}$. The beam incident was $15^{\circ}$ and the working distance from camera to sample was $14 \mathrm{~cm}$. The image size was 782 x 582 pixels. The images were kept at room temperature $20^{\circ} \mathrm{C}$. The light source was a solid state laser diode (Power Technology) module, emitting at 670,785 and $980 \mathrm{~nm}$ with an output power of $3 \mathrm{~mW}$ and $28.3 \mathrm{~mW}$ for, respectively. The large output power of the laser $980 \mathrm{~nm}$ is to compensate the loss of camera sensity in this spectral zone. These wavelengths were selected based on other studies (Peng et al, 2006; Qing et al, 2007). Backscattering light from samples was kept by monochromatic images (Figure 1) where it was possible observe to the two zones. Each image was analyzed with Matrox 8.0 Software. The gray scale of light intensity is expressed as the integer, which ranged from dark (0) to white (255).

\section{Texture}

Firmness was measured as the resistance needed by the fruit pulp, to penetrate (by force) $10 \mathrm{~mm}$ to the apple. The texture analyzer used (model TA.XT Plus Texture Analyzer, Texture Technologies (North American)) had a loading rate of $2 \mathrm{~mm} / \mathrm{sec}$. Fruit skin was removed prior to taking values in the area measured. The texture analyzer was equipped with a load cell of $5 \mathrm{kgf}$.

\section{Solid Soluble Content}

After firmness measurements, juice was extracted and SSC was measured using a digital refractometer (Model ATAGO PR-101 Co., Tokyo, Japan). 


\section{Statistical treatment}

\section{Partial Least Square analysis (PLS)}

PLS analysis is a regression method used often to construct prediction models of reference parameters taken from destructive methods. PLS allows the correlation between backscattering images with ripeness parameters. PLS has been used frequently in studies related to the prediction of quality indexes in various fruits and vegetable: avocados (Clark et al, 2003), nectarines (Sánchez et al, 2011) and asparagus (Pérez et al, 2002).

In this work, calibration models were developed to predict firmness and SST of intact apples. Cross-validation was used to avoid overfitting in the development of calibration models. Data management was performed using The Unscrambler X (CAMO) software.

Selection of samples for calibration and validation purposes is one of the critical steps when developing a calibration model. A random subdivision on calibration and validation data was performed, using a 2:1 ratio for calibration and validation respectively. A Principal Component Analysis (PCA) was performed to detect anomalous samples obtained from calibration models. The samples detected as anomalous were not included in the calibration groups.

Statistics used to select the best equations were: coefficient of determination for cross validation $\left(\mathrm{R}^{2}\right)$ and standard error of cross validation (SEVC)(Williams, 2001). Other statistics used were the coefficient of variation (\%CV), defined as the percentage ratio of the SECV to the mean value of the reference data for the calibration set, and the RPD (Residual Predictive Deviation) calculated as the ratio of the standard deviation (SD) of the reference data to the SECV (Williams, 2001). \%CV and RPD enable SECV to be standardized, facilitating in comparising the results obtained from sets of different means (Williams, 2001).

The best predictive models obtained were subsequently subjected to external validation. The effect of different settings on model performance was evaluated by comparing the root mean square error of prediction (RMSEP), coefficient of external validation $\left(\mathrm{r}^{2}\right)$, bias and standard error of prediction (SEP).

\section{RESULTS AND DISCUSSIONS}

PLS analysis constructed calibration models from destructive (SSC and firmness) and non-destructive measurements (backscattering images). Table 1 shows the number of samples for calibration, validation, mean values, standard deviation, range and coefficient of variation. The validation group range of validation is included in calibration, which demonstrates the group selection was made correctly.

Table 2 shows the statistical parameters obtained from the regression analysis. The $\mathrm{R}_{\mathrm{cv}}{ }^{2}$ values obtained were 0.93 and 0.87 for SSC and firmness, respectively. The number of principal components found in our calibration model were greater than values found in previous studies (Zude et al. 2007, $\mathrm{R}_{\mathrm{cv}}{ }^{2}=0.76,0.80$; and Lu, 2003, $\mathrm{R}_{\mathrm{cv}}{ }^{2}=0.77$ ). PLS results presented in this study were found to be more precise when compared to PLS values previously reported in other studies. Our large sample population size along with our diverse range of physical and chemical values assisted in obtaining more precise values. 
Figure 2 shows the external statistical validation performed on 69 samples. $r^{2}$ values were $r^{2}=0.86-0.74$ for SSC and firmness. With these results it is deduced that it is possible to obtain a good predictions in apple for the first, because the time of sampling has been very wide. It is necessary to continue working to construct better calibration models.

\section{CONCLUSIONS}

This study has demonstrated the possibility to apply nondestructive technique for the analysis of backscattering images to destructive quality parameters in apple 'Smoothee Golden Delicious'.

In the future, it is necessary to construct prediction models which are more precise.

It should be noted that this proposed methodology could be applied to any variety of apple.

\section{ACKNOWLEDGMENTS}

This work has been partially supported by the AGL2009-08501/AGR project from National Program of Research Projects.

I would like to thank Michael Krawitzky, Azahara Díaz, Ma Ángeles Gracia for their help

\section{REFERENCES}

[1]Chen, P. 1996. Quality evaluation technology for agricultural products. In: Proc. Int. Conf. on Agric. Machinery Engineering. Seoul. Korea

[2]Clark, C.J., McGlone, V.A., Requejo, C., White, A., Woolf, A.B. 2003. Dry matter determination in 'Hass' avocado by NIR spectroscopy. Postharvest Biology and Technology. Volume 29, pp. 300-307.Cover, T.M. and Thomas, J.A. 1991. Elements of Information Theory, Wiley, New York.

[3]López M.L., Lavilla M.T., Recasens I.,Graell J., Vendrell M., 2000. Changes in aroma quality of 'Golden Delicious' apples after storage at different oxygen and carbondioxide concentrations. Journal of the Science of Food and Agriculture, 80, 311-324

[4]Lu, R., 2004. Multispectral imaging to predicting firmness and soluble solids content of apple fruit. Postharvest Biology and Technology 31:147-157.

[5]Lu, R., Peng, Y., 2006. Hyperspectral scattering for assessing peach fruit firmness. Biosystem Engineering 93 (2), $161-171$.

[6]McGlone, V. and Kawano, S. 1998. Firmness, dry matter and soluble solids assessment of postharvest kiwifruit by NIR spectroscopy. Postharvest Biology and Technology 13:131-141.

[7]Peng, $\mathrm{Y}$ and $\mathrm{Lu}$, R. 2007. Prediction of apple fruit firmness and solid soluble content using characteristics of multispectral scattering images. Journal of Food Engineering 82 142-152. 
[8]Pérez-Marín, D., Sánchez, M.T., Cano, G. and Garrido, A. 2002. Prediction of texture in green asparagus by near infrared spectroscopy (NIRS). Journal Food Quality 25: 277-287.

[9]Qing, Z., Ji, B. and Zude, M. 2007.Wavelength selection for predicting physicochemical properties of apple fruit based on near-infrared spectroscopy. Journal of food quality. Volume 30, Issue 4, pp.511-526.

[10]Sánchez, M.T., De la Haba, M.J., Guerrero, J.E., Garrido-Varo, A. and Pérez-Marín, D. 2011. Testing of a local approach for the prediction of quality parameters in intact nectarines using a portable NIRS instrument. Postharvest Biology and Technology 60:130-135.

[11]Tu, K., De Busscher, R., De Baerdemaeker, J., Schrevens, E. 1995. Using laser beam as light source to study tomato and apple quality non-destructively. Food Processing Automation IV Conference, Chicago, IL, 3-5. November. Pp. 528536.

[12]Williams, P.C., 2001. Implementation of near-infrared technology. In: Williams, P.C.,Norris, K.H. (Eds.), Nearinfrared Technology in the Agricultural and Food Industries. AACC, Inc., St. Paul, MN, pp. 145-169.

\section{FIGURES}

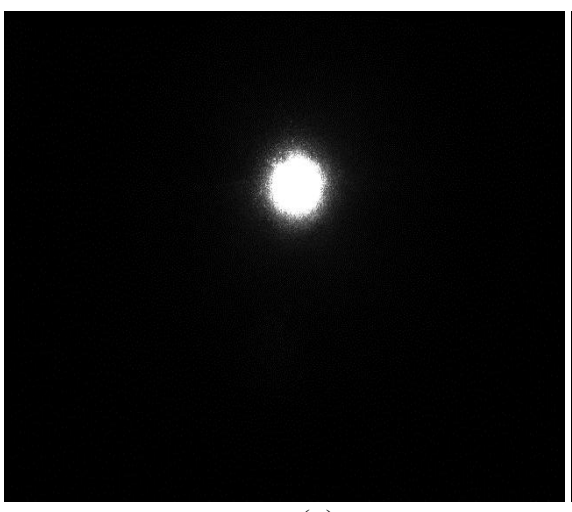

(a)

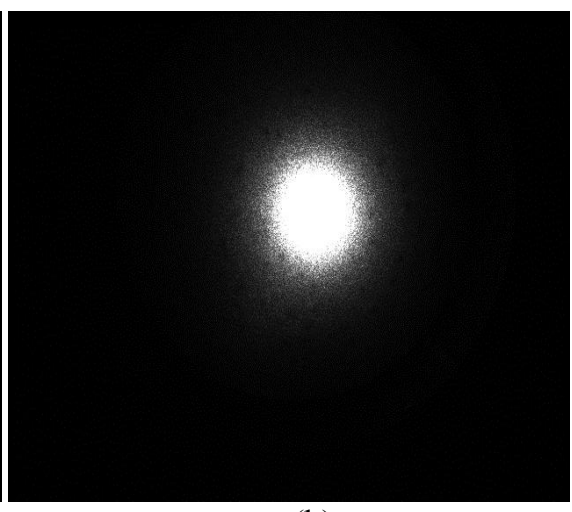

(b)

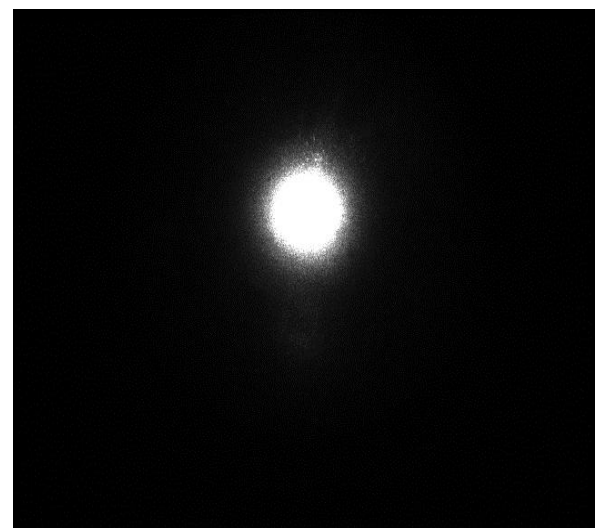

(c)

Figure 1. Multispectral images obtained with 670(a), 785(b) y 980(c) nm, respectively in 'Smoothee Golden Delicious' apple. 
Table 1.Mean, standard deviation, range and coefficient of variation for calibration and validation groups for SSC and firmness in 'Smoothee Golden Delicious' apple

\begin{tabular}{lcc|cc} 
& \multicolumn{2}{c}{ SSC } & \multicolumn{2}{c}{ Firmness } \\
\cline { 2 - 5 } & calibration & Validation & calibration & validation \\
\hline $\mathbf{N}$ & 139 & 69 & 139 & 69 \\
\hline Mean & 11.1 & 11.3 & 5.51 & 5 \\
DS & 2.2 & 2.2 & 2.28 & 1.78 \\
Range & $8.2-16.3$ & $8.2-15.5$ & $2.16-10.55$ & $2.74-9.18$ \\
\%CV & 19.4 & 19.1 & 41.46 & 35.59 \\
\hline
\end{tabular}

Table 2. Calibration statistics for SSC and firmness in 'Smoothee Golden Delicious' apple

\begin{tabular}{lcc} 
& PLS & \\
\hline & SST & Firmness \\
\hline $\mathbf{N}$ & 131 & 131 \\
PLS & 1 & 2 \\
SECV & 0.78 & 0.85 \\
$\mathbf{R}_{\mathbf{c v}}^{2}$ & 0.93 & 0.87 \\
RPD & 2.17 & 2.65 \\
\hline
\end{tabular}
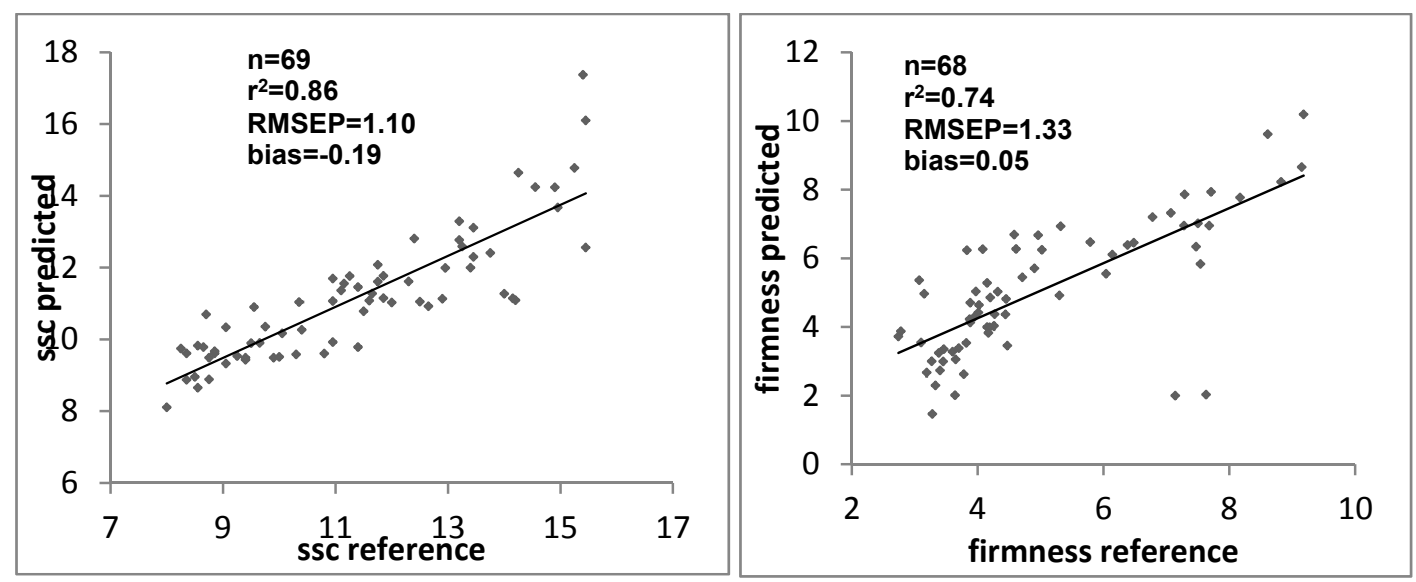

Figure 2. Prediction model for SSC and firmness in 'Smoothee Golden Delicious' apple 